\title{
PENGARUH PENGALAMAN BELANJA ONLINE, KEPUASAN PELANGGAN, DAN ADJUSTED EXPECTION TERHADAP NIAT MEMBELI KEMBALI MELALUI TRAVELOKA
}

\author{
Ni Made Maya Devi Theresia ${ }^{1}$ \\ I Made Wardana ${ }^{2}$ \\ ${ }^{1,2}$ Fakultas Ekonomi dan Bisnis Universitas Udayana (Unud), Bali,Indonesia \\ Email: mayadevi.theresia98@gmail.com
}

\begin{abstract}
ABSTRAK
Tujuan penelitian ini adalah untuk mengetahui pengaruh pengalaman belanja online, kepuasan pelanggan, dan adjusted expectations terhadap niat membeli kembali. Penelitian ini dilakukan pada Traveloka dengan sampel sebanyak 96 milenial yang berdomisili di Kabupaten Badung dan Kota Denpasar, dengan metode non probability sampling khususnya purposive sampling. Alat analisis yang digunakan dalam penelitian ini adalah PLS (Partial Least Square). Berdasarkan hasil analisis ditemukan bahwa pengalaman belanja online berpengaruh signifikan terhadap kepuasan pelanggan, semakin baik pengalaman belanja secara online yang didapat oleh pelanggan maka kepuasan pelanggan akan semakin meningkat. Pengalaman belanja online tidak berpengaruh signifikan terhadap adjusted expectations. Kepuasan pelanggan berpengaruh signifikan terhadap adjusted expectations, semakin tinggi tingkat kepuasan maka adjusted expectations juga akan semakin meningkat. Kepuasan pelanggan dan adjusted expectations berpengaruh signifikan terhadap niat membeli kembali.
\end{abstract}

Kata kunci : pengalaman, kepuasan, adjusted expectations, niat membeli kembali.

\begin{abstract}
The purpose of this study was to determine the effect of online shopping experience, customer satisfaction, and adjusted expectations on the intention to repurchase. This research was conducted at Traveloka with a sample of 96 millennials domiciled in Badung Regency and Denpasar City, with a non probability sampling method specifically purposive sampling. The analytical tool used in this study is PLS (Partial Least Square). Based on the results of the analysis it was found that online shopping experience had a significant effect on customer satisfaction, the better the online shopping experience obtained by the customer, the more customer satisfaction will increase. Online shopping experience does not have a significant effect on adjusted expectations. Customer satisfaction has a significant effect on adjusted expectations, the higher the level of satisfaction then adjusted expectations will also increase. Customer satisfaction and adjusted expectations have a significant effect on repurchase intention.

Keywords: experience, satisfaction, adjusted expectations, intention to epurchase.
\end{abstract}


Ni Made Maya Devi Theresia, Pengaruh Pengalaman Belanja...

\section{PENDAHULUAN}

Globalisasi merupakan suatu fenomena khusus dalam peradaban manusia yang bergerak terus menerus dalam masyarakat global dan merupakan bagian dari proses manusia global itu. Kehadiran teknologi informasi dan teknologi komunikasi mempercepat proses globalisasi (Surahman, 2013). Globalisasi memiliki pengaruh yang sangat besar terhadap perubahan gaya hidup masyarakat. Kemajuan teknologi yang semakin pesat merupakan salah satu dampak dari globalisasi yang menyebabkan adanya perubahan - perubahan perilaku masyarakat. Internet merupakan hasil dari kemajuan teknologi, pengaruh internet yang lambat laun semakin berkembang dalam kehidupan manusia sehari-hari ternyata dapat memengaruhi perilaku dan gaya hidup masyarakat (Dwipayana, 2017). Salah satu perubahan tersebut menyebabkan adanya tren baru yang sangat kita rasakan saat ini, yaitu perubahan perilaku pembelian masyarakat dari offline ke online (Santoso dan Atik, 2017).

Pada saat ini masyarakat sudah terhubung dengan internet di mana saja dan kapan saja dengan menggunakan komputer, smartphones, tablets, dan bahkan televisi (Kotler dan Gary ,2014a : 525). Internet telah mengubah secara mendasar gagasan pelanggan mengenai kenyamanan, kecepatan, harga, informasi, dan layanan. Sehingga, tidak dapat kita pungkiri bahwa kini sebagian besar masyarakat lebih memilih untuk melakukan segala transaksi belanja secara online.

Dampak dari pesatnya kemajuan teknologi tersebut menyebabkan adanya kenaikan jumlah pengguna internet. Pengguna internet di Indonesia pada tahun 2017 adalah 54,2 persen yaitu sebanyak 143,26 juta jiwa dari total penduduk 262 
juta jiwa yang mana pada tahun sebelumnya yaitu tahun 2016 pengguna internet hanya berjumlah 137,27 juta jiwa.

Di Indonesia sendiri pengguna internet terbesar yaitu pada tahun 2016 adalah sebesar 49,52 persen dengan rentang usia antara 19-34 tahun (Asosiasi Penyelenggara Jasa Internet Indonesia, survei 2017), yang mana penduduk dengan rentang usia tersebut merupakan generasi milenial. Generasi milenial merupakan generasi yang lahir diantara tahun 1982 - 2000 (Belch, 2015a : 41). Hal ini berarti bahwa generasi milenial lebih sering menggunakan internet baik mencari informasi , melakukan transaksi atau yang lainnya.

Selama setengah abad mendatang generasi milenial akan menjadi inovator utama dalam cara bagaimana masyarakat beroperasi, termasuk infrastruktur di semua bagiannya, oleh karena itu memerlukan perhatian pemasaran yang khusus (DeChane, 2014). Karena milenial mempengaruhi generasi yang lebih tua, dan adanya peningkatan kenyamanan pada generasi tua terhadap teknologi akibat pengaruh dari generasi milenial menyebabkan banyak harapan serta perilaku milenial yang menjadi standar konsumen (Forbes, 2014). Generasi milenial merupakan generasi yang sulit untuk di pahami (Belch, 2015b: 42), sehingga menyediakan layanan online yang kuat tidak dapat menjadi satu - satunya strategi yang bisa digunakan oleh marketers untuk menyasar generasi milenial. Penyediaan aplikasi, bahkan testimonials, promosi dan menciptakan pengalaman belanja online yang baik sangatlah penting, karena milenial lebih memilih mendaptkan informasi atau bertransaksi dengan menggunakan telepon genggam mereka. Kehilangan telepon genggamnya akan menjadi sebuah tragedi besar bagi 
milenial (Forbes, 2014). Generasi milenial tidak ingin mengahabiskan waktu melakukan sesuatu dengan cara tradisional, seperti menulis dalam kertas (Belch, 2015c :42).

Sebagian besar dari pengguna internet tersebut adalah generasi milenial yang menyebabkan semakin besarnya permintaan masyarakat akan produk dan jasa secara online. Hal ini mengakibatkan banyak perusahaan baik di bidang produk maupun jasa memanfaatkan peluang tersebut, sehingga melahirkan produk atau jasa yang dijual melalui media internet. Salah satunya adalah online travel agent Traveloka, yang dapat menjadi salah satu contoh adaptasi pemasaran dalam memenuhi kebutuhan generasi milenial yang sesuai dengan perilaku mereka. Menurut cnbc.com (2017) jumlah milenial yang membeli rumah dengan generasi sebelumnya akan jauh lebih sedikit, karena prioritas hidup mereka dengan generasi yang lebih tua jauh berbeda. Berdasarkan survei yang dilakukan oleh realtymogul.com (2017) sebanyak 47 persen orang dengan rentang usia 18 sampai dengan 34 tahun lebih memilih menghabiskan uang mereka untuk traveling daripada membeli rumah dibandingkan dengan generasi yang lebih tua hanya 26 persen yang mengatakan demikian.

Traveloka disini merupakan online travel agent (OTA) asal Indonesia yang sudah berdiri sejak 2012, yang didirikan oleh Ferry Unardi, Derianto Kusuma, dan Albert. Traveloka memiliki layanan online yang memudahkan penggunanya mengakses, mendapatkan infromasi serta bertransaksi di mana saja dan kapan saja. Pada awal terbentuknya Traveloka pada tahun 2012, Traveloka hanya menyediakan layanan pemesanan tiket pesawat online namun pada tahun 2014 
Traveloka mulai menyediakan jasa layanan reservasi kamar hotel online dan kini Traveloka menjadi situs resmi penyedia jasa layanan pemesanan tiket pesawat dan reservasi kamar hotel secara online (press.traveloka.com). Selama kurang lebih enam tahun Traveloka telah mendapatkan banyak rewards baik di dalam maupun di luar negeri. Meskipun Traveloka bukanlah pionir dalam online travel agent, namun ia telah berhasil menjadi yang nomor satu di Indonesia. Salah satu reward yang didapat oleh Traveloka berturut turut adalah menjadi Top Brand Indonesia dalam kategori situs booking kamar hotel online dari tahun 2015 hingga 2018.

Tabel 1.

Top Brand Indonesia Tahun 2015 - 2018 Kategori Situs Online Booking Kamar Hotel.

\begin{tabular}{clcc}
\hline Tahun & \multicolumn{1}{c}{ Merek } & $\begin{array}{c}\text { Top Brand } \\
\text { Index } \\
\text { (dalam \%) }\end{array}$ & TOP \\
\hline \multirow{2}{*}{2015} & traveloka.com & 60,3 & TOP \\
& agoda.com & 10,8 & TOP \\
& utiket.com & 8,5 & - \\
\multirow{2}{*}{2016} & traveloka.com & 59,6 & TOP \\
& trivago.co.id & 13,5 & TOP \\
& agoda.com & 11,6 & TOP \\
& traveloka.com & 59,8 & TOP \\
& trivago.co.id & 13,3 & TOP \\
& agoda.com & 9,4 & - \\
& Traveloka.com & 42,0 & TOP \\
& Trivago.co.id & 13,0 & TOP \\
& Pegi-pegi.com & 8,6 & \\
& & & \\
\hline
\end{tabular}

Sumber : topbrand-award.com, 2017

Meskipun Traveloka tetap menjadi pemimpin diantara online travel agent lainnya yang ada di Indonesia, namun Traveloka ternyata mengalami penurunan penjualan dalam booking kamar hotel yang mana dapat kita lihat pada Tabel 1 . Pada tahun 2015 market share Traveloka mencapai 60,3 persen namun pada tahun 2016 dan 2017 turun menjadi 59,6 persen dan 59,8 persen dan penurunan drastis 
Ni Made Maya Devi Theresia, Pengaruh Pengalaman Belanja...

pada tahun 2018 mencapai 42 persen. Penurunan yang dialami dapat menjadi masalah besar bagi Traveloka dalam situs booking kamar hotel jika tidak ditanggapi dengan serius. Strategi - strategi pemasaran harus lebih diperhatikan agar perusahaaan dapat mempertahankan market sharenya.

Menurunnya market share Traveloka di tengah maraknya situs online booking kamar hotel dikarenakan menurunnya niat menggunakan kembali pelanggan Traveloka yang disebabkan adanya ketidakpuasan pelanggan akan jasa Traveloka yang merupakan dampak dari pengalaman buruk yang mereka alami akan Traveloka dan harapan mereka terhadap Traveloka menurun. Fenomena ini juga dapat dikarenakan semakin gencarnya pesaing di bidang online travel agent dalam situs online booking kamar hotel. Sebagai contoh Trivago dan Agoda kedua online travel agent tersebut berasal dari luar Indonesia yang mana Trivago berasal dari Amerika dan Agoda berasal dari Singapore. Kedua online travel agent tersebut berlomba - lomba dan perlahan mengalami peningkatan market share.

Menurut (Bolton et al., 2013) generasi milenial mengapresiasi feedback dan memprogramkan untuk mengikuti petunjuk yang jelas. Traveloka memiliki layanan tersebut dalam aplikasi mereka guna membuat konsumen mereka puas. Oleh karena itu dapat dikatakan bahwa kepuasan konsumen dapat menjadi satu alasan kenapa para konsumen ingin melakukan niat pembelian ulang (Dwipayana, 2017).

Niat beli ulang termasuk di dalam tindakan pasca pembelian. Jadi, kepuasan atau ketidakpuasan pasca pembelian terhadap suatu produk sangat mempengaruhi perilaku konsumen selanjutnya. Selain itu variabel terbaik untuk memprediksi 
prilaku masa depan adalah pengalaman (Kotler dan Keller, 2009:190). Menurut Lin dan Watcharee (2013), adjusted expectations cendrung diperbaharui melalui pengalaman konsumsi yang terukur saat ini. Adjusted expectations atau harapan pasca pengalaman konsumsi, akan mengarahkan pelanggan untuk meningkatkan kepekaan terhadap produk atau layanan (Liao et al., 2010). Dalam konteks ini, jika kinerja produk atau jasa lebih tinggi dari harapan pelanggan pada awalnya, maka pelanggan akan senang dan mungkin akan terkejut, pelanggan yang puas adalah pelanggan yang dapat menyesuaikan tingkat harapannya (Lin dan Watcharee, 2013).

Kebiasaan belanja online yang lemah berasal dari kekhawatiran dalam melakukan transaksi melalui internet dan dengan pedagang yang tidak terpercaya, sehingga mempengaruhi niat pelanggan karena kurangnya kepuasan (Andreson dan Srinivasan, 2003). Dengan kata lain, pelanggan yang telah mengembangkan kebiasaan belanja online meningkatkan niat pembelian kembali melalui kepuasan pelanggan. Berkenaan pada pasca konsumsi, pelanggan akan menilai kinerja setelah transaksi selesai. Jika produk atau layanan membawa kepuasan dan kepuasan tingkat tinggi kepada pelanggan, maka kita dapat berasumsi bahwa harapan sebelumnya sangat disesuaikan (Lin dan Watcharee 2013). Berdasarkan fenomena diatas terdapat penelitian serupa yang sudah pernah dilakukan oleh Lin dan Watcharee pada tahun 2013, mengenai Factors Affecting Online Repurchase Intention yang meneliti tentang pengaruh pengalaman belanja online, customer satisfaction, dan adjusted expectations terhadap repurchase intention. Maka dari itu kali ini peneiliti akan melakukan replikasi terhadap penelitian terdahulu 
Ni Made Maya Devi Theresia, Pengaruh Pengalaman Belanja...

dengan menggunakan beberapa variabel yang sama namun objek dan lokasi penelitian yang berbeda. Adapun tujuan peneliti adalah untuk menguji dan menganalisis bagaimana pengaruh pengalaman belanja online, kepuasan pelanggan dan adjusted expectation terhadap niat membeli kembali melalui Traveloka. Pengujian studi ini dilakukan pada generasi milenial di Kabupaten Badung dan Kota Denpasar.

Berdasarkan latar belakang yang telah dipaparkan di atas dapat dirumuskan permasalahan sebagai berikut: Apakah pengalaman belanja online berpengaruh terhadap kepuasan pelanggan dalam menggunakan Traveloka. Apakah pengalaman belanja online berpengaruh terhadap adjusted expectations dalam menggunakan Traveloka. Apakah kepuasan pelanggan berpengaruh terhadap adjusted expectations dalam menggunakan Traveloka. Apakah kepuasan pelanggan berpengaruh terhadap niat membeli kembali pelanggan Traveloka. Apakah adjusted expectations berpengaruh terhadap niat membeli kembali pelanggan Traveloka.

Hasil penelitian ini secara teoritis diharapkan dapat menjadi referensi tambahan dan untuk memperkaya pengetahuan pembaca akan teori - teori dari perilaku konsumen, yang berhubungan dengan variabel pengalaman belanja online, kepuasan pelangan, adjusted expectations dan niat membeli kembali pada konsumen. Secara praktis diharapkan memberikan manfaat bagi pelaku bisnis khususnya Traveloka sebagai informasi tentang variabel yang berkontribusi terhadap perilaku konsumen dalam menggunakan kembali sebuah produk jasa. Selanjutnya untuk pemerintah bisa dipakai sebagai dasar dalam pengambilan 
kebijakan yang terkait dengan regulasi menambah variabel baru untuk memperluas hasil penelitian.

Generasi milenial memilih dan menggunakan produk yang membantu mereka untuk menjelaskan diri mereka. Mereka menggunakan pengetahuan mereka terhadap tren terbaru, images, produk, dan nama brand untuk mereka jadikan sebuah pertimbangan untuk membeli sesuatu. Mereka memiliki keinginan untuk membuat keputusan terbaik tidak hanya pada harga namun juga kualitas (Ordun, 2015). Generasi milenial merupakan generasi yang membeli produk sesuai dengan diri mereka dan memilih produk berbasis teknologi terbaru serta sangat mempertimbangkan kualitas produk dengan hargaserta ketersediaan produk tersebut dalam media sosial dan ketika produk tersebut sangat dapat merepresentasikan diri mereka maka mereka akan menjadi loyal.

Pengalaman belanja online menurut Ling et al. (2010) menyatakan bahwa jika pengalaman berbelanja online pada masa lalu dinilai negatif, pelanggan akan enggan untuk terlibat dalam belanja online pada masa depan. Hal ini menjelaskan pentingnya mengubah pembeli internet yang ada menjadi pembeli berkelanjutan dengan menyediakan pengalaman memuaskan belanja online. Selain itu pembelian online secara individu diawali dengan dengan pembelian kecil, setelah itu pembeli akan cenderung untuk mengembangkan kepercayaan diri dan keterampilan menggunakan online shopping tersebut untuk melakukan pembelian yang lebih besar melalui internet di lain waktu.

Kepuasan pelanggan terjadi ketika pelayanan atau produk memenuhi atau melampaui harapan konsumen itu sendiri (Tolba et al., 2015). Kepuasan 
Ni Made Maya Devi Theresia, Pengaruh Pengalaman Belanja...

pelanggan dapat didefinisikan sebagai keseluruhan sikap yang ditampilkan pelanggan berdasarkan perasaan yang dirasakan saat pelangan mendapatkan pelayanan atau produk sesuai dengan yang diharapkan pelanggan (Swari dan Giantari, 2017). Kepuasan pelanggan merupakan respon baik dari pelanggan atas produk yang mereka beli. Respon baik tersebut tercipta karena kepuasan mereka atas suatu produk.

Adjusted Expectations merupakan harapan yang terjadi setelah dilakukannya pembelian, dimana ekspektasi awal pembeli mengalami pembaharuan atas dasar pengalaman yang telah dialami (Yi dan La, 2004). Konsumen yang puas dengan pengalaman dari suatu pelayanan akan memiliki harapan yang lebih tinggi dari pelayanan tersebut untuk kedepannya, dan hal tersebut nantinya memunculkan adanya loyalitas. Memasukkan adjusted expectation akan memberikan penjelasan yang lebih baik untuk memahami bagaimana konsumen berperilaku (Rufin et al., 2012).

Niat membeli kembali secara online adalah situasi ketika seorang pelanggan bersedia dan berniat untuk terlibat dalam transaksi kegiatan pembelian yang sering dilakukan karena adanya minat untuk membeli produk yang sudah pernah dikonsumsi serta sudah merasakan manfaat dan kegunaan jasa maupun produk tersebut (Pavlou, 2003). Keputusan pembelian pada masa lalu oleh konsumen akan berdampak pada masa mendatang, hal tersebut berupa pembelian kembali yang kemudian menginformasikan kinerja produk atau jasa yang dirasakannya kepada orang lain (Kuntjara, 2007).

Tjandra dan Lydia (2018) menyatakan pelanggan yang sering melakukan 
pembelian secara onlinemendapat pengalaman dalam berbelanja online dan mengalami peningkatan kepuasan. Selain itu, Idris (2017) juga mengemukakan bahwa penglaman pelanggan akan berdampak secara signifikan terhadap kepuasan pelanggan akan suatu produk atau jasa.

$\mathrm{H}_{1}$ : Pengalaman belanja onlineberpengaruh secara positif signifikan terhadap kepuasan pelanggan.

Menurut Ha et al. (2010) jika konsumen mengalami perasaan yang baik di situs web, konsumen akan rela mengunjungi kembali situs web tersebut. Lebih khusus lagi, semakin banyak konsumen yang mengalami pengalaman positif, semakin tinggi harapan mereka kedepannya. Selain itu Tjandra dan Lydia (2018) menyatakan Pengalaman belanja online berpengaruh terhadap adjusted expectations artinya semakin sering konsumen berbelanja semakin meningkat harapan mereka pada toko online tersebut.

$\mathrm{H}_{2}$ : Pengalaman belanja online berpengaruh secara positif signifikan terhadap adjusted expectations.

Seorang pelanggan merasa puas dengan nilai yang diberikan oleh produk atau jasa, sangat besar kemungkinannya menjadi pelanggan dalam waktu yang lama. Hal tersebut didukung oleh penelitian Ha et al. (2010) yang menyatakan bahwa kepuasan pelanggan berpengaruh terhadap adjusted expectationspada service sektor. Selanjutnya Tjandra dan Lydia (2018) menyatakan hal yang sama bahwa kepuasan pelanggan berpengaruh terhadap adjusted expectations. Lin dan Watcharee (2013) dalam penelitiannya juga menyatakan bahwa dalam belanja online kepuasan pelanggan berpengaruh besar terhadap adjusted expectationsmaka dari itu sangat penting untuk pedagang online mengendalikan 
Ni Made Maya Devi Theresia, Pengaruh Pengalaman Belanja...

adjusted expectations.

$\mathrm{H}_{3}$ : Kepuasan pelanggan berpengaruh secara positif signifikan terhadapadjusted expectations.

Pada penelitian yang dilakukan Santoso dan Atik (2017) menyatakan bahwa customer satisfaction memiliki hubungan yang positif dengan repurchase intentionpada pengguna go-ride di Jawa.Studi sebelumnya juga dilakukan oleh Sanchez et al. (2012). Pelanggan yang puas cendrung untuk membeli kembali di masa yang akan datang di bandingkan pelanggan yang tidak puas, pelanggan akan kembali berkunjung untuk liburan ke destinasi yang sama.Adapun penelitian yang dilakukan oleh Oyedele et al. (2018) tentang smart wristband menyatakan bahwa jika pelanggan yang berusia muda yang merasa puas akan produk tersebut maka mereka akan berniat untuk membeli produk tersebut kembali.

$\mathrm{H}_{4}$ : Kepuasan pelanggan berpengaruh secara positif signifikan terhadap niat membeli kembali.

Yi dan La (2004) yang dalam penelitiannya pada pelanggan familyrestaurant di Korea menyatakan bahwa adjusted expectations berpengaruh positif terhadap repurchase intention. Menurut Lin danWatcharee (2013) menyatakan bahwa pedagang perlu meningkatkan ekspektasi konsumen agar membawa mereka untuk membeli kembali, semakin banyak pelanggan memiliki pengalaman dan perasaan yang baik, dan semakin tinggi ekspektasi yang tercapai dapat membuat konsumen membeli kembali. (Ha et al., 2010) menyebutkan bahwa dalam toko online jika program yang diberikan dapat meningkatkan harapan pelanggan maka pelanggan dapat meningkatkan pembelian kembali.

$\mathrm{H}_{5}$ : Adjusted expectationsberpengaruh secara positif signifikan terhadap niat membeli kembali. 


\section{METODE PENELITIAN}

Penelitian ini digolongkan sebagai penelitian asosiatif (hubungan), yaitu penelitian yang bertujuan untuk mengetahui hubungan dari dua variabel atau lebih.Metode ini digunakan untuk mengetahui pengaruh antara variabel pengalaman belanja online, kepuasan pelanggan, adjusted expectationsdan niat membeli kembali. Penelitian ini dilakukan di Kabupaten Badung dan Kota Denpasar.

Objek penelitian ini adalah niat membeli kembali Traveloka yang ditinjau berdasarkan pengaruh pengalaman belanja online, kepuasan pelanggan dan adjusted expectations. Adapun subjek dari penelitian ini adalah generasi milenial yang berdomisili di Kabupaten Badung dan Kota Denpasar. Generasi milenial dengan rentang umur 18 - 35 tahun yang lahir pada tahun 1982 - 2000 (Belch, $2015 \mathrm{~d}: 42)$.

Populasi dalam penelitian ini adalah generasi milenial yang berdomisili di Kabupaten Badung dan Kota Denpasar yang mana para milenial ini sudah pernah melakukan reservasi atau booking kamar hotel menggunakan Traveloka. Jumlah populasi yang di gunakan dalam penelitian ini tidak dapat ditentukan secara pasti atau infinite. jumlah sampel yang digunakan dalam penelitian ini sebanyak 16 × 6 $=96$ sampel.

Penelitian ini menggunakan metode pemilihan sampel Non-probability sampling yang merupakan pemilihan sampel secara tidak acak. Menurut Rahyuda (2016:145) terdapat beberapa teknik penarikan non-probability sampling, dan 
Ni Made Maya Devi Theresia, Pengaruh Pengalaman Belanja...

yang digunakan dalam penelitian ini adalah purposive sampling yaitu penarikan sampel berdasarkan tujuan dari peneliti dengan pertimbangan tertentu.

Data primer dalam penelitian ini adalah berupa data hasil penyebaran kuesioner. Data sekunder dalam penelitian ini adalah berupa jurnal, artikel buku dan institusi atau pihak lain yang mempublikasikan data yang dikutip terkait dengan topik penelitian ini. Data kuantitatif, dalam penelitian ini sadalah data top brand awards Indonesia, data pengguna internet Indonesia dan data hasil scoring tanggapan responden terhadap kuisioner. Sedangkan data kualitatif dalam penelitian ini adalah berupa jenis - jenis layanan pada Traveloka dan perusahaan - perusahaan yang menjadi mitra Traveloka.

Metode pengumpulan data yang digunakan dalam rencana penelitian ini adalah metode survei dengan cara menyebarkan kuisioner, yang disebarkan kepada responden yang berkaitan dengan pengaruh pengalaman belanja online, kepuasan pelanggan, adjusted expectationsterhadap niat membeli kembali melalui Traveloka. Skala pengukuran yang digunakan dalam penelitian ini adalah skala Likert.

Teknik analisis yang digunakan dalam penelitian ini adalah statistik deskriptif digunakan untuk mendeskripsikan karakteristik responden dan variabelvariabel penelitian (Sugiyono, 2016 :169). Bentuk statistik inferensial yang digunakan dalam penelitian ini adalah Partial Least Squares (PLS), dimana PLS merupakan salah satu metode analisis yang bisa diterapkan untuk seluruh skala data, tidak memerlukan asumsi yang banyak, ukuran sampelnya tidak diharuskan besar, dapat dipergunakan untuk pembuktian teori, dan juga dapat digunakan 
untuk mengembangkan hubungan yang belum mempunyai landasan teori yang kuat.

\section{HASIL DAN PEMBAHASAN}

Karakteristik responden penelitian merupakan profil dari 96 responden yang telah berpartisipasi dalam pengisian kuesioner penelitian ini. Profil responden memaparkan jenis kelamin, usia, pendidikan terakhir dan pekerjaan. Secara lebih jelas, karakteristik responden disajikan pada Tabel 2. berikut :

Tabel 2.

Karakteristik Responden

\begin{tabular}{ccccc}
\hline No. & Karakteristik & Klasifikasi & $\begin{array}{c}\text { Jumlah } \\
\text { Orang }\end{array}$ & $\begin{array}{c}\text { Presentase } \\
(\mathbf{\%})\end{array}$ \\
\hline 1. & Jenis kelamin & Laki- laki & 48 & 50 \\
& & Perempuan & 48 & 50 \\
2. & Jumlah & $18-23$ & 96 & 100 \\
& Usia & $24-29$ & 60 & 62,5 \\
& & 27 & 28,1 \\
3. & Jumlah & 9 & 9,4 \\
& Pendidikan & SMA/Sederajat & 38 & 100 \\
& terakhir & Diploma & 3 & 39,6 \\
& & Sarjana & 49 & 3,1 \\
& & Pascasarjana & 6 & 51,1 \\
& & 96 & 6,2 \\
4. & Jumlah & Pelajar & 38 & 100 \\
& Pekerjaan & PNS/ANS & 2 & 29,6 \\
& & Wiraswasta & 2 & 2,1 \\
& & Karyawan & 54 & 56,2 \\
& & 96 & 100 \\
\hline
\end{tabular}

Sumber: Data primer diolah, 2018

Menurut data yang tersaji pada Tabel 2. tentang karakteristik responden, berdasarkan kriteria jenis kelamin, jumlah responden laki - laki dan perempuan adalah sama yaitu masing - masing berjumlah 48 orang dengan presentase sama besar yaitu 50 persen. Responden dengan rentang usia 18 - 23 tahun mendominasi dengan presentase 62,5 persen. 
Tabel 3.

Hasil Uji Validitas dan Reliabilitas Instrumen Penelitian

\begin{tabular}{|c|c|c|c|c|c|c|}
\hline Variabel & & Indikator & $\begin{array}{c}\text { Pearson } \\
\text { Correla } \\
\text { tion }\end{array}$ & $\begin{array}{c}\text { Keteranga } \\
\mathbf{n}\end{array}$ & $\begin{array}{l}\text { Cronba } \\
\text { h's } \\
\text { Alpha }\end{array}$ & $\begin{array}{c}\text { Keterang } \\
\text { an }\end{array}$ \\
\hline \multirow{4}{*}{$\begin{array}{l}\text { Pengalaman } \\
\text { belanja } \\
\text { online }\end{array}$} & $\mathrm{X}_{1}$ & Shop & 0,680 & Valid & \multirow[b]{4}{*}{0,780} & \multirow[b]{4}{*}{ Reliabel } \\
\hline & $\mathrm{X}_{2}$ & extensively & 0,693 & Valid & & \\
\hline & $X_{3}$ & Have been & 0,678 & Valid & & \\
\hline & $\mathrm{X}_{4}$ & $\begin{array}{l}\text { shop } \\
\text { Accessibility } \\
\text { Experience } \\
\text { involvement }\end{array}$ & 0,819 & Valid & & \\
\hline \multirow{4}{*}{$\begin{array}{l}\text { Kepuasan } \\
\text { pelanggan }\end{array}$} & $\mathrm{Y}_{1.1}$ & Feel satisfied & 0,801 & Valid & \multirow{4}{*}{0,825} & \multirow{4}{*}{ Reliabel } \\
\hline & $\mathrm{Y}_{1.2}$ & $\begin{array}{l}\text { Satisfies my } \\
\text { needs }\end{array}$ & 0,793 & Valid & & \\
\hline & $\mathrm{Y}_{1.3}$ & $\begin{array}{l}\text { Satisfied with } \\
\text { experience }\end{array}$ & 0,861 & Valid & & \\
\hline & $\mathrm{Y}_{1.4}$ & Right decision & 0,884 & Valid & & \\
\hline \multirow{5}{*}{$\begin{array}{l}\text { Adjusted } \\
\text { Expectation } \\
S\end{array}$} & $\mathrm{Y}_{2.1}$ & $\begin{array}{l}\text { Efficient } \\
\text { transaction }\end{array}$ & 0,782 & Valid & \multirow{5}{*}{0,794} & \multirow{5}{*}{ Reliabel } \\
\hline & $\mathrm{Y}_{2.2}$ & $\begin{array}{l}\text { Informative } \\
\text { description of } \\
\text { products }\end{array}$ & 0,748 & Valid & & \\
\hline & $\mathrm{Y}_{2.3}$ & Offer what I & 0,708 & Valid & & \\
\hline & $\mathrm{Y}_{2.4}$ & $\begin{array}{l}\text { seek } \\
\text { Overall }\end{array}$ & 0,708 & Valid & & \\
\hline & $\mathrm{Y}_{2.5}$ & $\begin{array}{l}\text { pleasing } \\
\text { experience } \\
\text { Needs will be } \\
\text { fulfilled }\end{array}$ & 0,828 & Valid & & \\
\hline \multirow{3}{*}{$\begin{array}{l}\text { Niat } \\
\text { membeli } \\
\text { kembali }\end{array}$} & $\mathrm{Y}_{3.1}$ & $\begin{array}{l}\text { Intend to } \\
\text { repurchase }\end{array}$ & 0,924 & Valid & \multirow{3}{*}{0,865} & \multirow{3}{*}{ Reliabel } \\
\hline & $\mathrm{Y}_{3.2}$ & Will continue & 0,911 & Valid & & \\
\hline & $Y_{3.2}$ & Will regularly & 0,886 & Valid & & \\
\hline
\end{tabular}

Sumber: Data primer diolah, 2018

Tabel 3. menunjukkan bahwa seluruh instrumen dalam variabel pengalaman belanja online, kepuasan pelanggan, harapan yang disesuaikan dan niat membeli kembali memiliki pearsoncorrelation yang lebih besar dari angka 0,30. Dapat disimpulkan bahwa seluruh instrumen variabel dalam penelitian ini adalah valid sehingga dapat digunakan sebagai instrumen penelitian. Berdasarkan hasil uji reliabilitas, seluruh Cronbach's Alpha menunjukkan nilai lebih dari 0,6. Hal tersebut menunjukkan bahwa semua instrumen reliabel atau memiliki konsistensi atau kehandalan dalam mengukur variabel dalam penelitian ini, sehingga dapat 
digunakan untuk melakukan penelitian.

Evaluasi model dalam PLS terbagi menjadi dua model yaitu model pengukuran (outer model) dan model struktural (inner model). Adapun tabel outer loading dalam penelitian ini adalah sebagai berikut.

Tabel 4.

Outer loadings

\begin{tabular}{ccccc}
\hline & $\begin{array}{c}\text { Adjusted } \\
\text { Expectations }\end{array}$ & $\begin{array}{c}\text { Kepuasan } \\
\text { Pelanggan }\end{array}$ & $\begin{array}{c}\text { Niat } \\
\text { Membeli } \\
\text { Kembali }\end{array}$ & $\begin{array}{c}\text { Pengalaman } \\
\text { Belanja Online }\end{array}$ \\
\hline AE1 & 0,808 & & & \\
AE2 & 0,876 & & & \\
AE3 & 0,905 & & & \\
AE4 & 0,914 & & & \\
AE5 & 0,894 & 0,882 & & \\
KP1 & & 0,890 & & \\
KP2 & & 0,908 & & \\
KP3 & & 0,929 & 0,963 & \\
KP4 & & & 0,953 & \\
NMK1 & & & 0,891 & \\
NMK2 & & & & 0,591 \\
NMK3 & & & & 0,837 \\
PBO1 & & & & 0,911 \\
PBO2 & & & \\
PBO3 & & & \\
PBO4 & & & \\
\hline
\end{tabular}

Sumber: Data primer diolah, 2018

Tabel 4. memperlihatkan bahwa nilai outer model telah memenuhi kriteria convergent validity, semua indikator memiliki loading factor di atas 0,50, sehingga dapat disimpulkan bahwa tidak ada permasalahan convergent validity pada model yang diuji.

Uji validitas konvergen juga dilakukan dengan cara melihat nilai AVE. Adapun tabel AVE dalam penelitian ini adalah sebagai berikut.

Tabel 5. memperlihatkan bahwa nilai AVE telah memenuhi kriteria convergent validity, seluruh variabel memiliki nilai AVE di atas 0,50 sehingga dapat disimpulkan bahwa tidak ada permasalahan convergent validity pada model 
yang diuji.

Tabel 5.

Nilai Average Variance Extracted (AVE)

\begin{tabular}{ll}
\hline \multicolumn{1}{c}{ Konstruk } & AVE \\
\hline Adjusted Expectations & 0,775 \\
Kepuasan pelanggan & 0,814 \\
Niat Membeli Kembali & 0,876 \\
Pengalaman Belanja Online & 0,678 \\
\hline Sumber: Data primer diolah, 2018
\end{tabular}

Tabel 6.

Validitas Diskriminan

\begin{tabular}{|c|c|c|c|c|}
\hline & $\mathbf{A E}$ & KP & NMK & PBO \\
\hline $\mathrm{AE}$ & 0,880 & & & \\
\hline KP & 0,659 & 0,902 & & \\
\hline NMK & 0,590 & 0,611 & 0,936 & \\
\hline $\mathrm{PBO}$ & 0,570 & 0,784 & 0,560 & 0,824 \\
\hline
\end{tabular}

Tabel 6. menunjukkan bahwa nilai akar kuadrat dari AVE $(0,880,0,902,0,936,0,824)$ lebih besar dari korelasi masing - masing konstruk. Dengan demikian dapat dikatakan bahwa tidak masalah dalam model penelitian jika dilihat dari validitas diskriminan.

Tabel 7.

Cronbach's Alpha

\begin{tabular}{lcc}
\hline \multicolumn{1}{c}{ Variabel } & $\begin{array}{c}\text { Cronbach's } \\
\text { Alpha }\end{array}$ & $\begin{array}{c}\text { Composite } \\
\text { Realibility }\end{array}$ \\
\hline Adjusted Expectations & 0,927 & 0,944 \\
Kepuasan Pelanggan & 0,924 & 0,946 \\
Niat Membeli Kembali & 0,929 & 0,955 \\
Pengalaman Belanja Online & 0,837 & 0,892 \\
\hline
\end{tabular}

Sumber: Data primer diolah, 2018

Berdasarkan Tabel 7. menunjukkan bahwa nilai cronbach's alpha untuk seluruh variabel memiliki nilai lebih dari 0,6 sehingga dapat disimpulkan bahwa tidak ada permasalahan realibilitas / unidimensionalitas pada model yang di bentuk. Nilai composite realibility untuk seluruh variabel memiliki nilai lebih dari 0,7 sehingga dapat disimpulkan bahwa tidak ada permasalahan realibilitas 
unidimensionalitas pada model yang di bentuk.

Setelah model yang diestimasi memenuhi kriteria outer model, berikutnya dlakukan pengujian model struktural (inner model) yang bertujuan untuk mengetahui goodness of fit dengan metode - metode berikut:

Tabel 8.

\begin{tabular}{lcc}
\multicolumn{3}{c}{ Nilai R - squares } \\
\hline \multicolumn{1}{c}{ Variabel } & $\mathrm{R}-$ square & Kriteria \\
\hline Adjusted Expectations & 0,441 & Moderat \\
Kepuasan Pelanggan & 0,615 & Kuat \\
Niat Membeli Kembali & 0,436 & Moderat \\
Pengalaman Belanja Online & & \\
Sumber: Data primer diolah, 2018 & &
\end{tabular}

Data pada Tabel 8. menunjukkan bahwa nilai R-square variabel adjusted expectations sebesar 0,441 yang tergolong moderat, yang dapat diinterpretasikan bahwa 44,1 persen variabilitas konstruk adjusted expectationsdijelaskan oleh variabel pengalaman belanja online, sedangkan 55,9 persen variabel adjusted expectations dijelaskan oleh variabel di luar model. R-square variabel kepuasan pelanggan sebesar 0,615 yang tergolong kuat, yang mana 61,5 persen variabilitas konstruk kepuasan pelanggan dijelaskan oleh variabel pengalaman belanja online, sedangkan sebanyak 38,5 persen variabel kepuasan pelanggan dijelaskan oleh variabel di luar model. Demikian juga dengan R-squareniat membeli kembali sebesar 0,436 tergolong moderat yang artinya 43,6 persen variabilitas konstruk niat membeli kembali dijelaskan oleh variabel pengalaman belanja online, sedangkan 56,4 persen variabilitas konstruk niat membeli kembali dijelaskan oleh variabel di luar model.

Nilai $Q$-Square (Predictive Relevance) dapat dihitung sebagai berikut : 
$\mathrm{Q}^{2}=1-\left(1-\mathrm{R}^{2}{ }_{1}\right)\left(1-\mathrm{R}^{2}{ }_{2}\right)\left(1-\mathrm{R}^{2}{ }_{3}\right)$.

$\mathrm{Q}^{2}=1-(1-0,441)(1-0,615)(1-0,436)$

$\mathrm{Q}^{2}=1-(0,559)(0,385)(0,564)$

$\mathrm{Q}^{2}=1-0,12$

$\mathrm{Q}^{2}=0,88$ atau $88 \%$

Hasil perhitungan $Q$ - Square (Predictive Relevance) menghasilkan nilai $88 \%$ memiliki arti bahwa model memiliki nilai observasi yang baik. Artinya $88 \%$ hubungan antar variabel dapat dijelaskan oleh model. Berdasarkan kedua hasil perhitungan diatas $\mathrm{R}^{2}$ dan $\mathrm{Q}^{2}$ dengan kriteria model yang kuat dan baik, maka dapat dilanjutkan dengan analisis pengujian hipotesis.

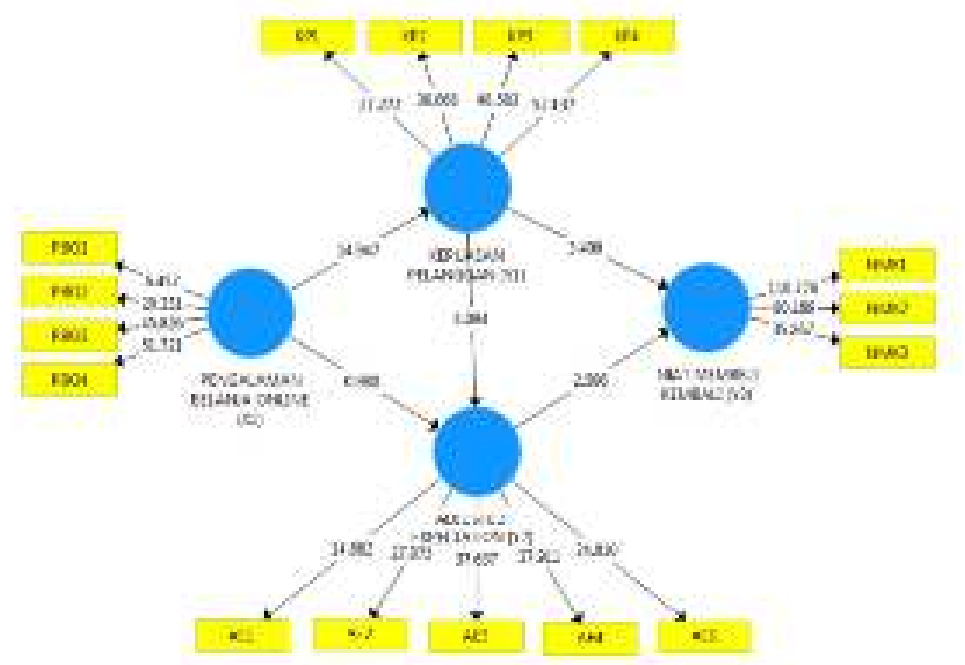

Gambar 1. Diagram Jalur Model Analisis Sumber: Data diolah, 2018.

Output estimasi untuk pengujian model struktural akan dijelaskan pada Tabel 9. sebagai berikut : 
Tabel 9.

Path Coefficient (Mean, STDEV, T-Values, P-Values)

\begin{tabular}{lccccc}
\hline & $\begin{array}{c}\text { Sampel } \\
\text { Asli }(\boldsymbol{O})\end{array}$ & $\begin{array}{c}\text { Sampel } \\
\text { Mean (M) }\end{array}$ & $\begin{array}{c}\text { Standar } \\
\text { Deviasi } \\
\text { (STDEV) }\end{array}$ & $\begin{array}{c}\text { T Statistik } \\
(\text { OS/STERR })\end{array}$ & $\begin{array}{c}\boldsymbol{P} \text {. } \\
\text { Values }\end{array}$ \\
\hline $\mathrm{AE}\left(\mathrm{Y}_{2}\right)->\mathrm{NMK}\left(\mathrm{Y}_{3}\right)$ & 0,331 & 0,312 & 0,120 & 2,766 & 0,005 \\
$\mathrm{KP}\left(\mathrm{Y}_{1}\right)->\mathrm{AE}\left(\mathrm{Y}_{2}\right)$ & 0,550 & 0,547 & 0,128 & 4,286 & 0,000 \\
$\mathrm{KP}\left(\mathrm{Y}_{1}\right)->\mathrm{NMK}\left(\mathrm{Y}_{3}\right)$ & 0,393 & 0,409 & 0,109 & 3,605 & 0,000 \\
$\mathrm{PBO}(\mathrm{X})->\mathrm{AE}\left(\mathrm{Y}_{2}\right)$ & 0,139 & 0,138 & 0,139 & 0,997 & 0,312 \\
$\mathrm{PBO}(\mathrm{X})->\mathrm{KP}\left(\mathrm{Y}_{1}\right)$ & 0,784 & 0,787 & 0,047 & 16,784 & 0,000 \\
\hline Sumber: Data primer diolah, 2018 & & & &
\end{tabular}

Pada penelitian ini telah ditentukan sebelumnya nilai T-tabel dengan signifikansi pa $\alpha=0.05$ dengan nilai T- Statistik lebih besar dari t-hitung $(1,986)$. Empat dari lima koefisien jalur pada tabel 9. memiliki nilai T-Statistik di atas 1.986 sehingga dinyatakan memiliki pengaruh yang signifikan, akan tetapi satu koefesien jalur memliki nilai T- Statistik dibawah 1.986 sehingga dapat dikatakan bahwa tidak berpengaruh secara signifikan.

\section{Tabel 10.}

\begin{tabular}{|c|c|c|c|c|}
\hline \multicolumn{5}{|c|}{ F-Square } \\
\hline & $\mathbf{A E}$ & KP & NMK & PBO \\
\hline $\mathrm{AE}$ & & & 0,110 & \\
\hline KP & 0,208 & & 0,155 & \\
\hline NMK & & & & \\
\hline PBO & 0,013 & 1,596 & & \\
\hline
\end{tabular}

Nilai effect size berada diantara $0-1$, beberapa penelitian kerap menghasilkan effect size lebih dari satu. Berdasarkan Tabel 10. diatas, hubungan antar variabel adjusted expectationsdengan niat membeli kembali adalah siginfikan namun memiliki efek yang lemah karena memiliki effect size sebsar 0,110 yang berada dalam rentang $0-0,20$ dengan kategori lemah. Begitu juga dengan hubungan antar variabel kepuasan pelanggan terhadap niat membeli kembali adalah signifikan namun memiliki efek yang lemah karena memiliki effect size sebesar 0,155 yang berada dalam rentang lemah. Hubungan antar variabel 
Ni Made Maya Devi Theresia, Pengaruh Pengalaman Belanja...

kepuasan pelanggan terhadap adjusted expectations memiliki hubungan yang signifikan dan memiliki efek sedang karena memiliki effect size sebesar 0,208. Hubungan antar variabel pengalaman belanja online dan adjusted expectations dalam penelitian ini adalah tidak signifikan dan memiliki efek yang lemah karena memiliki effect size sebesar 0,013. Selanjutnya hubungan antar variabel pengalaman belanja online terhadap kepuasan pelanggan memiliki hubungan yang signifikan dan efek yang sangat kuat karena memiliki effect size sebesar 1,596 (> 1) dan masuk dalam kategori sangat kuat.

Tabel 11.

Nilai Path dan Uji Hipotesa

\begin{tabular}{|c|c|c|c|c|}
\hline \multicolumn{2}{|c|}{ Hubungan Variabel } & Path & P-Value & Hipotesis \\
\hline $\mathrm{PBO}(\mathrm{X})$ & $->\mathrm{KP}\left(\mathrm{Y}_{1}\right)$ & 0,784 & 0,000 & Diterima \\
\hline $\mathrm{PBO}(\mathrm{X})$ & $->\operatorname{AE}\left(\mathrm{Y}_{2}\right)$ & 0,139 & 0,319 & Ditolak \\
\hline $\mathrm{KP}\left(\mathrm{Y}_{1}\right)$ & $->\operatorname{AE}\left(\mathrm{Y}_{2}\right)$ & 0,550 & 0,000 & Diterima \\
\hline $\mathrm{KP}\left(\mathrm{Y}_{1}\right)$ & $->\operatorname{NMK}\left(\mathrm{Y}_{3}\right)$ & 0,393 & 0,000 & Diterima \\
\hline $\mathrm{AE}\left(\mathrm{Y}_{2}\right)->$ & $\operatorname{NMK}\left(\mathrm{Y}_{3}\right)$ & 0,331 & 0,005 & Diterima \\
\hline
\end{tabular}

Tabel 11. menunjukkan bahwa empat hubungan memiliki hubungan yang positif dan signifikan, hanya ada satu hubungan yang tidak signifikan dengan membandingkan P-Value lebih kecil dari alpha 0,05.

Pengalaman belanja online berpengaruh positif signifikan terhadap kepuasan pelanggan pengguna Traveloka. Hal ini berarti bahwa semakin baik pengalaman belanja onlineyang didapat oleh pelanggan Traveloka yang dalam penelitian ini adalah generasi milenial yang berdomisili di Kabupaten Badung dan Kota Denpasar, maka akan semakin tinggi pula tingkat kepuasannya terhadap Traveloka. 
Hasil ini sejalan dengan penelitian terdahulu yang dilakukan oleh Tjandra dan Lydia (2018) menyatakan pelanggan yang sering melakukan pembelian secara onlinemendapat pengalaman menarik dalam berbelanja online dan mengalami peningkatan kepuasan.Selain itu Idris (2017) juga mengemukakan bahwa penglaman pelanggan akan berdampak secara signifikan terhadap kepuasan pelanggan akan suatu produk atau jasa.

Pengalaman belanja online tidak berpengaruh signifikan terhadap adjusted expectations pengguna Traveloka. Hal ini berarti bahwa meskipun pengalaman belanja onlineyang didapat oleh pelanggan pada pembelian sebelumnya memuaskan namun hal tersebut tidak berpengaruh pada adjusted expectationspada pembelian selanjutnya karena tingkat harapan bisa sangat bervariasi tergantung pada apa yang menjadi poin referensi pelanggan dan faktor - faktor luar yang dapat mempengaruhi, melihat bahwa dalam konteks ini yang diteliti adalah online travel agent yang mana sesuatu yang bersifat online dapat berkembang dengan sangat cepat. Maka dari itu pengalaman belanja online tidaklah berpengaruh bagi milenial untuk tingkat harapan mereka pada pembelian selanjutnya.

Hasil ini sejalan dengan penelitian yang dilakukan oleh Lin dan Watcharee, (2013) yang dalam penelitiannya terhadap 1000 online shopper di Taiwan menyatakan bahwa pengalaman belanja online tidak berpengaruh terhadap adjusted expectations. Hipotesis diatas justru bertolak belakang dengan penelitian yang dilakukan oleh Tjandra dan Lydia, (2018) menyatakan pengalaman belanja online berpengaruh terhadap adjusted expectationsartinya semakin baik pengalaman konsumen dalam berbelanja maka akan semakin meningkat harapan 
mereka pada toko online tersebut. Hal tersebut juga didukung oleh penelitian $\mathrm{Ha}$ et al. (2010) yang menyatakan jika konsumen mengalami pengalaman yang menyenangkan di situs web, konsumen akan rela mengunjungi kembali situs web tersebut. Lebih khusus lagi, semakin banyak konsumen yang mengalami pengalaman positif, semakin tinggi harapan mereka kedepannya.

Kepuasan pelanggan berpengaruh positif signifikan terhadapadjusted expectations pada pengguna Traveloka. Hal ini berarti bahwa semakin puas pelanggan yang dalam penelitian ini adalah generasi milenial yang berdomisili di Kabupaten Badung dan Kota Denpasar, maka tingkat harapan pada pembelian selanjutnya akan semakin tinggi juga.

Hasil ini sejalan dengan penelitian yang dilakukan oleh Ha et al. (2010) yang menyatakan bahwa kepuasan pelanggan berpengaruh terhadap adjusted expectations pada service sektor. Tjandra dan Lydia, (2018) menyatakan hal yang sama bahwa kepuasan pelanggan berpengaruh terhadap adjusted expectations. Lin dan Watcharee, (2013) dalam penelitiannya juga menyatakan bahwa dalam belanja onlinekepuasan pelanggan berpengaruh besar terhadap adjusted expectationsmaka dari itu sangat penting untuk pedagang onlinemengendalikan harapan pelanggan yang disesuaikan.

Kepuasan pelanggan berpengaruh positif signifikan terhadap harapan yang disesuaikan pada pengguna Traveloka. Hal ini berarti semakin puas pelanggan yang dalam penelitian ini adalah generasi milenial yang berdomisili di Kabupaten Badung dan Kota Denpasar, maka mereka akan semakin berniat untuk melakukan pembelian kembali. 
Hal ini sejalan dengan penelitian yang dilakukan oleh Santoso dan Atik (2017) menyatakan bahwa customer satisfaction memiliki hubungan yang positif dengan repurchase intentionpada pengguna go-ride di Jawa.Studi sebelumnya oleh Sanchez - Garcia et al. (2012) Pelanggan yang puas cendrung untuk membeli kembali di masa yang akan datang di bandingkan pelanggan yang tidak puas, pelanggan akan kembali berkunjung untuk liburan ke destinasi yang sama.Adapun penelitian yang dilakukan oleh Oyedele et al. (2018) tentang smart wristband menyatakan bahwa pelanggan dengan usia muda yang merasa puas akan produk tersebut maka mereka akan berniat untuk membeli produk tersebut kembali.

Adjusted Expectations berpengaruh positif signifikan terhadap niat membeli kembali pada pengguna Traveloka. Hal ini berarti bahwa semakin tinggi tingkat harapan generasi milenial pasca pembelian terhadap Traveloka maka akan semakin tinggi juga niat mereka untuk membeli kembali.

Hal ini sejalan dengan penelitian yang dilakukan oleh Yi dan La (2004) yang dalam penelitiannya pada pelanggan family-restaurant di Korea menyatakan bahwa adjusted expectations berpengaruh positif terhadap repurchase intention. Selanjutnya menurut Lin dan Watcharee, (2013) pedagang perlu meningkatkan ekspektasi konsumen agar membawa mereka untuk membeli kembali, semakin tinggi ekspektasi yang tercapai maka dapat membuat konsumen membeli kembali. Selain itu menurut Ha et al. (2010), dalam toko online jika program yang diberikan dapat meningkatkan harapan pelanggan maka pelanggan dapat meningkatkan pembelian kembali.

\section{SIMPULAN}


Ni Made Maya Devi Theresia, Pengaruh Pengalaman Belanja...

Berdasarkan tujuan penelitian, rumusan masalah dan hasil penelitian dengan pembahasan yang telah dipaparkan sebelumnya, maka dapat diambil kesimpulan sebagai berikut: Pengalaman belanja online berpengaruh secara positif dan signifikan terhadap kepuasan pelanggan. Pengalaman belanja online tidak berpengaruh secara positif signifikan terhadap adjusted expectations. Kepuasan pelanggan berpengaruh secara positif dan signifikan terhadap adjusted expectations. Pelanggan Traveloka dalam booking kamar hotel akan mengalami peningkatan harapan atau muncul harapan - harapan baru jika pelanggan merasa puas akan kinerja Traveloka.

Kepuasan pelanggan berpengaruh secara positif dan signifikan terhadap niat membeli kembali. Hal ini berarti semakin puas pelanggan dalam menggunakan Traveloka untuk booking kamar hotel, maka niat untuk membeli kembali juga akan meningkat. Adjusted expectation berpengaruh secara positif dan signifikan terhadap niat membeli kembali.

Berdasarkan hasil penelitian tersebut, berikut adalah saran yang diharapkan dapat membantu pihak Traveloka dan peneliti selanjutnya yaitu : Kepuasan pelanggan memiliki pengaruh yang lebih besar dibandingkan adjusted expectation dalam meningkatkan niat membeli kembali. Maka dari itu, pihak Traveloka sebaiknya tetap menjaga layanan dan kinerjanya agar pelanggan terus merasa puas tiap kali akan menggunakan Traveloka untuk booking kamar hotel. Penting bagi pihak Traveloka untuk mengantisipasi adjusted expectation yang juga dapat mempengaruhi niat membeli kembali. Tetap menciptakan pengalaman yang baik bagi pelanggan yang serta merta akan meningkatkan kepuasan merupakan hal 
yang penting untuk meningkatkan niat membeli kembali.

\section{REFERENSI}

Adesegun Oyedele, Roberto Saldivar, Monica D. Hernandez and Emily Goenner. (2017). Modeling Satisfaction and Repurchase Intentions of Mobile Smart Wristbands: The Role Of Social Mindfulness And Perceived Value. Journal of International Marketing Review, 19 (3), 237-250.

Belch, George. E. dan Michael. A, Belch. (2015). Adevrtising and Promotion:An Integrated Marketing communications Perspective, $10^{\text {th }}$ Global ed. McGraw Hill education.

Bolton, R., Parasuraman, A., Hoefnagels, A., Michels, N., Kabadayi, S., Gruber, T., Solnet, D. (2013). Understanding Generation Y and their use of social media: A review and research agenda.Journal of Service Management, 24(3), 245-267.

Dechane, D.J. (2014). How To Explain The Millennial Generation? Understand The Context. Sociology Journal, 6(3).

Dwipayana, Bagus dan Eka Sulistyawati. (2017). Peran Kepuasan Dalam Memediasi Pengaruh Kepercayaan Terhadap Niat Beli Ulang Pada GoFood (Studi Kasus Pada Mahasiswa Fakultas Ekonomi Dan Bisnis Non Reguler Universitas Udayana). E-jurnal Manajemen Unud, 4(4), 2015: 813-831.

Ha, H., Janda, S., \& Muthaly, S. K. (2010). A new understanding of satisfaction model in e-re-purchase situation. European Journal of Marketing,44(7),997-1016. https://doi.org/10.1108/03090561011047490

Idris, Alien Dayinta Mahendra. (2017). Pengaruh Faktor Atribut Produk, Persepsi Nilai, Dan Pengalaman Konsumen Terhadap Minat Beli Ulang Yang Dimediasi Oleh Kepuasan Konsumen. Diponegoro Journal of Management 6(4),1-9.

Kotler dan Keller. (2009). Manajemen Pemasaran. Jilid 1, Edisi 13. Jakarta : Erlangga.

Kotler, Philip and Gary Armstrong. (2014). Principles of Marketing Global Edition fifteenth edition. United Kingdom : Pearson.

Ling, K.C., Chai, L.T., dan Piew, T.H. (2010). The Effects of Shopping Orientations, Online Trust and Prior Online Purchase Experience toward Customers' Online Purchase Intention. International Business Research, $3(3)$. 
Ni Made Maya Devi Theresia, Pengaruh Pengalaman Belanja...

Lin, C. (2014). Factors affecting online repurchase intention. Industrial Management and Data System, 114(4), 597-611. https://doi.org/10.1108/IMDS-10-2013-0432

Rahyuda, Ketut. (2016). Metode Penelitian Bisnis. Denpasar: Udayana University Press.

Santoso, A., \& Aprianingsih, A. (2017). The Influence of Perceived Service and E Service Quality to Repurchase Intention the Mediating Role of Customer Satisfaction Case Study: Go-Ride in Java. Journal of Business and Management, 6(1), 32-43.

Sugiyono. (2017). Metode Penelitian Kuantitatif, Kualitatif, dan R\&D. Bandung: Alfabeta.

Surahman, Sigit. (2013). Dampal Globalisasi Media Terhadap Seni Dan Budaya Indonesia. Jurnal Komunikasi Program Studi Ilmu Komunikasi Fakultas Ilmu Sosial dan Ilmu Politik Universitas Serang Raya, 2(1), 29-38.

Tjandra, Alfred dan Dr. Lydia Ari Widyarini. (2018). Pengaruh Pengalaman Belanja Online, Kepuasan Pelanggan, Adjusted Expectation Terhadap Niat Pembelian Ulang Pada Lazada.Co.Id. E-Jurnal Universitas Katolik Widya Mandala Surabaya, 6(2): 104-115

Yi, Y,. and La, S. (2004). What Influences the Relationship Between Customer Satisfaction and Repurchase Intention? Investigating the Effects of Adjusted Expectations and Customer Loyalty. Journal of Psychology \& Marketing, 21(5), 351-373. 